\title{
Effectiveness of Ultrasound Simulation in Obstetrics and Gynecology Education: A State-of-the-Art Review
}

\author{
${ }^{1}$ Sushila Arya, ${ }^{2}$ Alok Dwivedi, ${ }^{3}$ Zuber D Mulla, ${ }^{4}$ Sanja Kupesic Plavsic
}

\begin{abstract}
Introduction: The benefits and uses of ultrasound (US) are well documented for procedural and diagnostic purposes. A number of studies have evaluated the utility of simulation-based US training in achieving competency and improving safety. To the best of our knowledge, no previous studies have attempted to synthesize the effectiveness of US simulation in Obstetrics and Gynecology (OB GYN) education using a systematic method. This review article summarizes the effect of US simulation on learning outcomes in OB GYN with three objectives: (1) To review and summarize the available evidence on the effectiveness of US simulation in OB GYN; (2) determine the validity and usefulness of US simulation in OB GYN training; and (3) describe advantages and disadvantages of various US simulators available in OB GYN as of 2016.
\end{abstract}

Materials and methods: We performed a literature search using different search engines, such as Medline PubMed and EMBACE using appropriate keywords. The data were extracted from all published eligible studies. A meta-analysis was conducted in order to obtain a pooled estimate of effect of US simulation in OB GYN education based on the availability of data on common outcomes.

Results: The majority of the included studies supported the usefulness or validity of simulation training in OB GYN for the enhancement of US skills. The US simulation significantly improved the skills necessary to measure crown-rump length and nuchal translucency accurately.

Conclusion: Despite the cost, integration of US simulators in medical education appears to have a positive impact on the scanning and interpretation skills of trainees. This study may

\footnotetext{
${ }^{1}$ Assistant Professor, ${ }^{2}$ Assistant Professor and Director ${ }^{3}$ Assistant Dean and Professor, ${ }^{4}$ Associate Dean, Professor and Director

${ }^{1}$ Department of Obstetrics and Gynecology, Paul L. Foster School of Medicine, Texas Tech University Health Sciences EI Paso, EI Paso, Texas, USA

${ }^{2}$ Department of Obstetrics and Gynecology, Paul L. Foster School of Medicine; Biostatistics and Epidemiology Consulting Lab, Texas Tech University Health Sciences El Paso, El Paso Texas, USA

${ }^{3,4}$ Department of Faculty Development; Department of Obstetrics and Gynecology; Center for Advanced Teaching and Assessment in Clinical Simulation, Paul L. Foster School of Medicine, Texas Tech University Health Sciences EI Paso, EI Paso, Texas, USA

Corresponding Author: Sanja Kupesic Plavsic, Associate Dean for Faculty Development; Professor, Department of Obstetrics and Gynecology; Director, Center for Advanced Teaching and Assessment in Clinical Simulation Center for Advanced Teaching and Assessment in Clinical Simulation, Paul L. Foster School of Medicine, Texas Tech University Health Sciences El Paso, El Paso, Texas, USA, e-mail: sanja.kupesic@ttuhsc.edu
}

assist in preparing a dedicated curriculum for OB GYN US education via the inclusion of US simulation.

Keywords: Clinical skills, Gynecology, Obstetrics, Training, Ultrasound education, Ultrasound simulation

How to cite this article: Arya S, Dwivedi A, Mulla ZD, Kupesic Plavsic S. Effectiveness of Ultrasound Simulation in Obstetrics and Gynecology Education: A State-of-the-Art Review. Donald School J Ultrasound Obstet Gynecol 2017;11(2):115-125.

\section{Source of support: Nil}

Conflict of interest: None

\section{INTRODUCTION}

Ultrasound (US) is the most commonly used diagnostic tool for prenatal assessment and evaluation of various gynecological pathologies. While US is continuously enhancing the practice of obstetrics and gynecology (OB GYN), there is lack of standard curriculum and performance assessment tools to monitor trainees' improvement. There is a wide range of US skills among trainees and practitioners. Training standards and assessment of competency are not standardized among residency programs. In today's OB GYN training programs, US skills are primarily gained through clinical exposure at the cost of patient discomfort and safety. Training in US is highlighted as a top deficiency by residents. ${ }^{1}$ Due to insufficient competency at the basic level, there is a concern over safety and efficiency of US examination performed by resident physician novices. Patient encounters with novices who do not have appropriate training can lead to compromised patient care, unnecessary intervention, and additional testing. ${ }^{2,3}$ In a recent survey of 70 OB GYN residents, $50 \%$ of them failed to achieve US competencies required for the stage of training and reported limited exposure to dedicated US sessions, while $73 \%$ of them considered US simulation to be an essential component of their residency training which may improve their clinical and interpretation skills. ${ }^{4}$ The US is operator-dependent, requires manual dexterity and eye-hand coordination, as well as a thorough understanding of anatomy, physiology, and pathophysiology. Also, US training is timeconsuming and requires extensive exposure to various normal and abnormal clinical scenarios. ${ }^{5}$

The American Institute of Ultrasound in Medicine (AIUM) has provided guidelines and standards for US training. They require 3 months of US training or a 
minimum of 300 US examinations as a part of a residency or fellowship before independently performing and interpreting female pelvic US. ${ }^{6}$ The International Society of Ultrasound in Obstetrics and Gynecology (ISUOG) has published guidelines for basic US training for residents and suggested a minimum of $200 \mathrm{OB}$ scans for residents in OB GYN. ${ }^{7,8}$ The US skills correlate with number of scans or procedures performed, and may be influenced by duty hour restrictions of trainees and reduced exposure time to US training. ${ }^{9,10}$ In the current era, educators focus on achieving sufficient competence to deliver safe and effective patient care in a nontraditional method like simulated environment. Residents, fellows, and sonography students should be exposed to simulation-based training to maximize learning within few duty hours, achieve the highest possible performance level before US encounters with real patients, and improve patient safety.

A recent narrative review describes the US simulators used in OB GYN. ${ }^{11}$ However, this study does not provide information on the effectiveness of US simulation for US training and its validity. Until now there have been no attempts to analyze the overall evidence of the educational and competence benefits of US simulation and the transferability of simulation skills to the clinical OB GYN using a systematic review. We intend to summarize the effectiveness of US simulators in improving the performance of US skills in OB GYN with the following specific aims: (1) To review and summarize the available evidence on the effectiveness of US simulation in OB GYN; (2) determine the validity and usefulness of US simulation; and (3) describe advantages and disadvantages of various US simulators in OB GYN available as of 2016.

\section{MATERIALS AND METHODS}

\section{Data Analysis}

A literature search was performed within the electronic databases MEDLINE, PubMed, and EMBASE ${ }^{\circledR}$. A total of 128 articles were obtained initially using the combination of search terms "US simulator OR US simulation" AND "Obstetrics and Gynecology" AND "US education or education" AND "clinical performance OR clinical skills or learning outcomes" AND/OR "validity". Any studies, which evaluated the impact of US simulation education on at least one learning outcome in OB GYN US, such as accuracy in measuring biometry, were included in this review. Review articles, non-English articles, and abstracts were excluded from the study.

A manual review of titles and abstracts produced 78 articles, which met the inclusion criteria. Further examination of the full articles and the identification of duplicates revealed that 63 articles did not meet the inclusion criteria. Sixteen articles met the inclusion criteria and were included in this systematic review. The outcomes and conclusion of each study were summarized. A metaanalysis was carried out using a fixed effect models to obtain a pooled estimate for the satisfaction proportion and crown-rump length (CRL) outcome.

\section{RESULTS}

With rare exception, all of the studies on the usefulness or validity of simulation training in OB GYN reported an enhancement in US skills after the use of simulation. ${ }^{1}$ Table 1 summarizes the studies assessing the characteristics and outcomes of OB GYN US simulation. ${ }^{11-18}$ Over a span of 13 years, we identified 10 articles which evaluated the impact of the use of US simulation training on different outcomes in OB GYN. The majority of these studies evaluated the effect of US simulation through varying study designs, such as a prepost experimental study, ${ }_{1}^{11,14}$ nonrandomized interventional study, ${ }^{13,16}$ observational study, ${ }^{12,15}$ and randomized clinical trial. ${ }^{17}$ Of these studies, most of them $(n=9)$ were based on small sample sizes $(\leq 50)$. The two randomized studies produced contradictory findings; Skupski et $\mathrm{al}^{17}$ reflected that simulationbased training showed inferiority compared to live model in regards to the primary outcomes (rating of training, scanning technique, and image acquisition), while Tolsgaard et $\mathrm{al}^{12}$ demonstrated that simulation-based US training improved the performance compared to clinical training only. The latter study performed a randomized trial using a control, clinical training only group.

\section{First Trimester Screening}

Of the total studies included in this review, two assessed the impact of US simulation training on CRL and nuchal translucency (NT) measurements. ${ }^{13,14}$ These two studies found that US simulation significantly improves the skills required to measure CRL and NT accurately and may reduce false results.

\section{Anatomy Scan}

US is used to evaluate fetal anatomy and detect fetal structural abnormalities. ${ }^{15}$ The incidence of fetal anomalies is $2 \%$ for major, and $5 \%$ for minor anomalies. ${ }^{16-18,26}$ Compared with other diagnostic tools, the sensitivity of US in detecting anomalies is far less than perfect since a lot depends on the operator. Some multicenter studies from the early 1990s demonstrated no reduction in perinatal morbidity or mortality since the introduction of US. ${ }^{27,28}$ We may argue that this outcome is a consequence of the current training style, which involves theoretical knowledge gained by means of lectures and textbooks, and practical knowledge gained by exposure to as many patients as possible. The currently available high-fidelity 


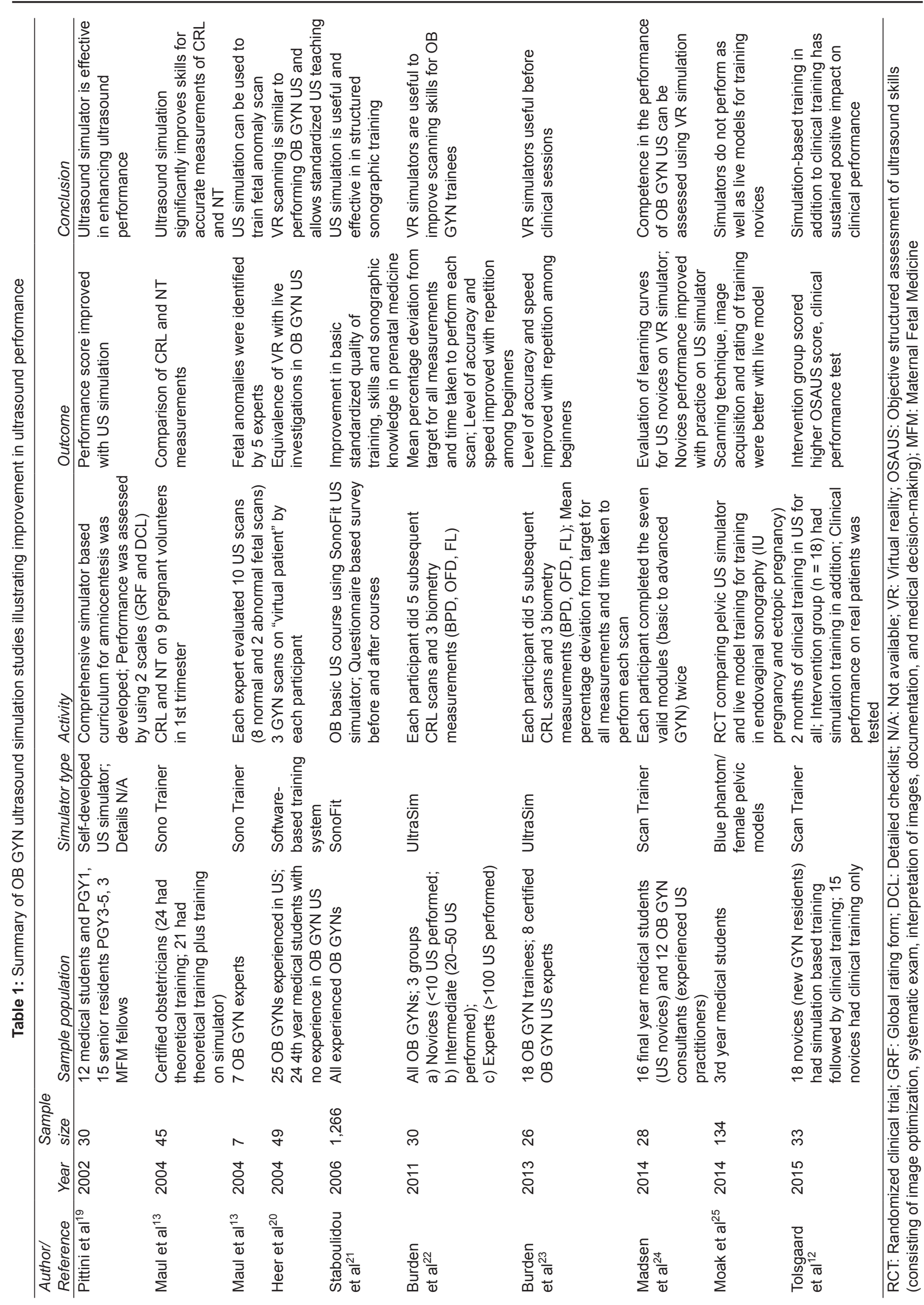


US simulators can simulate almost every imaginable US examination and may ultimately reduce the need of hired models and patients for early learning. The systematic use of US simulation may improve the detection rate of congenital fetal anomalies; improve the learning curve, self-assessment, and objective evaluation of the learner's competency. ${ }^{13}$ The training agenda for individual trainees can be modified depending on the desired pace of the acquisition of the required skills.

\section{Biometry}

SonoTrainer was used by experts and demonstrated improvement in accurate CRL and NT measurements and supported the idea of introducing simulationbased training into clinical learning. ${ }^{13}$ The majority of participants reported good image quality and excellent training effect with the use of SonoTrainer US simulator. Using UltraSim, Burden et $\mathrm{al}^{23}$ reported improvement in efficiency in obtaining biometry measurements, the accuracy (mean deviation in the measurements of fetal biometry from target values), and placental localization. They also reported that the simulator was easy to be used by novices as well as experienced operators and noticed quick adaptation to the simulator. ${ }^{29} \mathrm{Akoma} \mathrm{et} \mathrm{l}^{30}$ evaluated the role of a fetal pig simulator in OB US training in 24 participants who were randomized to two groups with 12 learners in each group. Only hands-on scanning on pregnant patients was used for the first group (patients between 16 and 28 weeks gestation), and hands-on scanning plus fetal pig simulation for the second group. No difference in biometric scan between the two groups was observed, but the intervention group (hands-on scanning plus fetal pig simulation) obtained improvement in scanning time and the acquisition of adequate images. The conclusion of this study was that the addition of a fetal pig US task trainer improved US scan efficiency.

\section{Prenatal Procedures}

Since the focus in health care is shifting to better prenatal outcomes per center, in-training physicians should achieve the best skills possible in order to perform critical procedures that can improve fetal survival. Teaching and training can be challenging especially for "not so commonly performed procedures" like fetal surgeries. The rate of invasive procedures has dropped significantly in the past 6 years due to the increased use of improved screening tests. ${ }^{31}$ The use of noninvasive cell-free fetal DNA testing is likely to continue to cause a decline in the use of invasive testing. In order to increase the expertise of fellows within the limitation of a declining number of invasive procedures, the role of simulation should be explored and the American Congress of Obstetricians and Gynecologists (ACOG) should consider guidelines to maximize trainees' experience. ${ }^{32}$ Rose et $\mathrm{al}^{33}$ indicated that simulation-based training may help preserve and improve those procedural skills.

Amniocentesis, chorionic villi sampling (CVS), inutero stent placement, percutaneous umbilical cord blood sampling, and cervical cerclage are the areas where simulation has great potential benefit. ${ }^{34}$ It is anticipated that more fetal surgeries will be performed in the future due to the increasing incidence of multiple gestation (increasing use of assisted reproductive technologies and advanced maternal age), economic growth, and heightened awareness of fetal surgeries. McWeeney et $\mathrm{al}^{35}$ reported that maternal-fetal medicine (MFM) fellowship programs are not able to provide sufficient training in CVS. Therefore, they developed a novel training model using a porcine heart, piglet, and freezer bag with US gel to simulate abdominal wall and use of transabdominal sonogram to guide CVS performance. All MFM faculty and fellows agreed that the model was useful. ${ }^{35}$ Nitsche et al ${ }^{36}$ created a novel in-utero stent placement training model using a gravid pig uterus. This kind of low-cost task trainer was utilized to enhance skills in a nonclinical environment. Zubair et al $^{37}$ developed a novel amniocentesis model by using formalin-preserved gravid pig uterus and a freezer bag filled with US gel placed on the top of the uterus to simulate the abdomen. Changing the fetal position and amniotic fluid and gel thickness simulated realistic scenarios. Simulation-based curriculum examples helped trainees learn amniocentesis early in their training with no discomfort to patients from practice trials. ${ }^{38}$ Peeters et $\mathrm{al}^{39}$ reported improved performance of fetoscopic laser surgery in twin-to-twin transfusion syndrome with the use of advanced high-fidelity simulator. Experts as well as novices reported the usefulness of simulators and felt that the use of simulation improved their performance score and reduced procedure time. Similarly, the use of a task trainer for simulation of ultrasound-guided second trimester uterine evacuation improved proficiency and confidence with dilatation and evacuation procedures among residents and other trainees. ${ }^{40}$

\section{Pelvic Ultrasound}

Madsen et $\mathrm{al}^{24}$ reported that the virtual reality (VR) simulator is a reliable and valid tool to improve pelvic US examination performance. In their study various advanced pelvic modules were used and authors observed improvement in novices' performance, which plateaued after 4 hours of simulation training. Girzadas et $\mathrm{al}^{41}$ demonstrated improvement in knowledge, diagnostic skills, and management of a ruptured ectopic pregnancy using a hybrid simulator compared to a standard high-fidelity simulator. The hybrid simulator consisted 
of a transvaginal US task trainer combined with a highfidelity US mannequin. Vallabh-Patel et $\mathrm{al}^{4}$ reported improvement in clinical knowledge and interpretation of images skills in a clinical setting with the use of lowand high-fidelity transabdominal and transvaginal pelvic US simulators. Monsky et al also reported improved knowledge and scanning ability following early pelvic US simulation for residents. ${ }^{42}$

\section{Ultrasound Learning for Trainees}

Steps should be taken to develop a standard curriculum, dedicated and effective training for OB GYN residents, fellows and practicing physicians to improve and preserve their US scanning and interpretation skills. Credible performance standards should be reached before encounters with actual patients. Based on our systematic review, there is a benefit of including simulation courses and dedicated curricula for different level of trainees using different modules. A standard US curriculum, similar to what was developed for MFM fellowships, which incorporates the introduction of US simulation at an early stage for the novices in OB GYN training is of paramount importance. ${ }^{43}$ For improvement in US education among OB GYN residents and its subspecialties, clear educational goals and objectives, and valid performance rating should be established. ${ }^{44,45}$

Three major competencies in US are as follows: (1) Technical aspect of performance, (2) image perception, and (3) interpretation - medical decision-making skills. ${ }^{2,45,46}$ For the objective assessment of US skills, international multispecialty consensus suggested seven elements: (1) Indication for the examination; (2) applied knowledge of US equipment; (3) image optimization; (4) systematic examination; (5) interpretation of images; (6) documentation of examination; and (7) medical decision-making. ${ }^{47}$

\section{Validity of Various Simulators}

Limitations of the first generation of VR simulators are static images of the fetus, lack of heart activity, and no blood flow. Additionally, there is no adiposity effect and given the increasing prevalence of obesity the addition of this feature in upcoming advanced simulators will be very helpful. These real-time properties of US simulation were improved in recent models. Most studies variably demonstrated acquisition of knowledge and skills and generated findings, suggesting a correlation with simulation training and improved performance in the simulated environment. ${ }^{12,19-25,13}$ This finding may be acceptable provided the simulator is appropriately validated (in many reports, i.e., debatable). Some studies examined the question of validity concurrently or in isolation, so there is limited evidence on construct validity of simulators. ${ }^{11,14,29,48-50}$ Though literature on the use of US simulation is sparse, it consistently showed its usefulness in US education in OB GYN.

Burden et al demonstrated construct validity of the UltraSim simulator in performance of CRL and growth scan measurements, and stated that this high-fidelity simulator has the potential to improve the scanning skills of OB GYN trainees. ${ }^{51}$ Newey et $\mathrm{al}^{14}$ have demonstrated the validity of VirUS for NT measurement. More recently, Patel et al ${ }^{51}$ explored the OB GYN trainees' perspective on the use of VR US simulation in the United Kingdom. Of 140 trainees, $70(50 \%)$ responded to the survey; $73 \%$ of respondents considered US simulation to be an essential component of training; 69\% agreed that it helps improving their clinical skills; $77 \%$ would like to have US simulation integrated into OB GYN training. Table 2 reviews the studies evaluating the validity of OB GYN US simulators. ${ }^{17,22,24-26,33,51}$

There is limited reported evidence on the transferability and sustained effect of US simulation training-based skills to the clinical setting. This paucity of literature could be due to the lack of simulator metric validity and a standard measuring tool for performance. Figure 1 shows the satisfactory rating of US simulators in the improvement of clinical knowledge and image interpretation skills in the clinical setting. The pooled meta-analysis showed a high satisfactory rating proportion of $84 \%$ (95\% confidence interval: 79-90\%) without significant heterogeneity $(68.7 \%$ considering $70 \%$ or more as presence of heterogeneity).

\section{Types of US Simulators}

Currently, there are three types of US simulators.

1. Online: Web-based programs that use mouse-operated controls to change scan planes and simulate probe manipulation, and display US images corresponding to the particular scan plane. To our knowledge, there is no clinical validation of this method.

2. High-fidelity mannequins: Consisting of the mannequin, simulator, US probe, computer, and monitor. The display uses virtual anatomic model images with augmented reality and US rendered images or actual US images from a stored dataset.

3. Phantoms: Use of a real US unit to image a phantom to practice diagnostic and/or procedural skills (e.g., echocardiograms-solid heart model to demonstrate cardiac anatomy and scan planes, amniocentesis phantom, etc.).

Table 3 reviews the currently available OB GYN US simulators. ${ }^{11,16,17,22,33,48-51,52-73}$

\section{Limitations of OB GYN US Simulation}

The inconsistency in study design and measurement items across the studies that were included in our review 


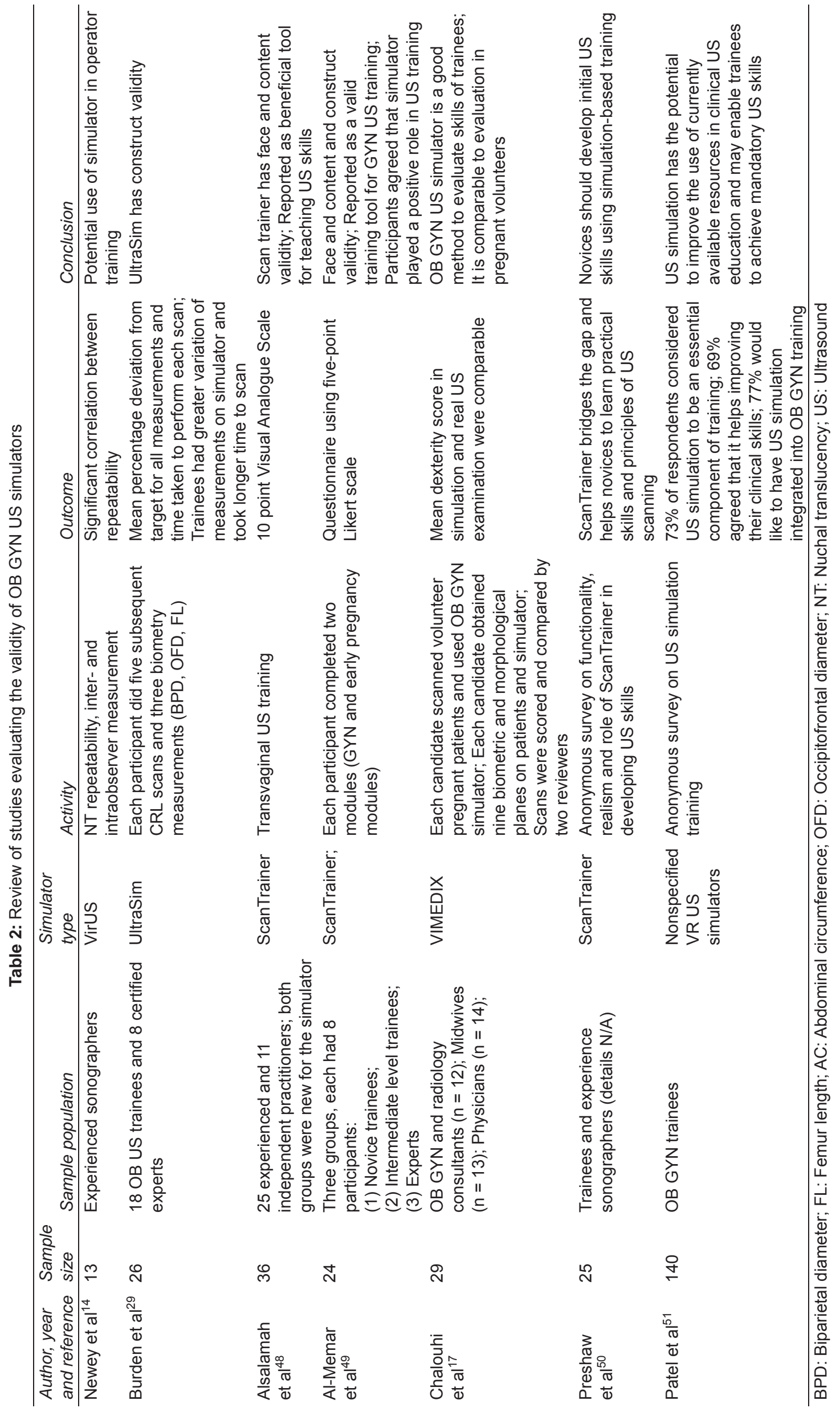




\begin{tabular}{|c|c|c|c|}
\hline Study & Year & Proportion $(95 \% \mathrm{Cl})$ & $\%$ Weight \\
\hline Staoulidou et al & 2006 & $0.90(0.81,0.96)$ & 31.32 \\
\hline Aisalamahetal & 2014 & $0.840 .67,0.94)$ & 22.75 \\
\hline Vallabh-patel et al & 2016 & $0.69(0.56,0.79)$ & 25.32 \\
\hline Al-memar & 2016 & $0.88(0.68,0.97)$ & 20.61 \\
\hline \multicolumn{2}{|c|}{ Overall (1-squared $=68.2 \%, p=0.024$} & $0.83(0.73,0.93)$ & 100.00 \\
\hline \multicolumn{2}{|c|}{ Note: weights are from random effects analysis } & & \\
\hline
\end{tabular}

Fig. 1: Rating of ultrasound training using simulators

precluded a broader meta-analysis of the effect of US simulation on OB GYN education. In most studies the scoring system used to measure improvement was not standardized and pre- and posttest analysis was not done consistently. In some studies a control group was lacking, and the US experience of comparison groups was not clear. Our review did not include the results of unpublished research studies and non-English language studies, and a more comprehensive review of the "gray" literature was not performed. Despite the limitations stated above, nearly all of the included studies reported substantial improvement in clinical knowledge, skills, and confidence following the use of OB GYN US simulation.

\section{CONCLUSION}

In surgical fields simulation-based training has already been incorporated, with proven benefit in procedural skills. ${ }^{52-54}$ Simulators are not perceived as a replacement of clinical training but rather as an aid to speed up the basic, as well as advanced skills learning curve. A simulator is an educational tool, which imitates reallife scenarios, closely approximates patient encounters to develop knowledge and skills that can be transferred to the clinical setting to improve patient safety and efficiency. The goal of simulation is to help the learners become more confident and competent when caring for their patients. ${ }^{55}$ Additional benefit of simulation is the reduction of patient discomfort. Simulation also provides an opportunity for independent learning and limits the need of supervision. The US simulation is expected to improve efficiency and diagnostic skills resulting in the decreased need of expensive imaging tools, such as computed tomography and magnetic resonance imaging. Simulation-based training is gaining more popularity in all medical specialties, and following the introduction of simulation improved outcomes have been widely reported. ${ }^{44,56}$ The US simulation is a safe, effective, and learner-centered educational approach which improves image optimization and probe orientation, provides the opportunity for unlimited practice without pressure, and facilitates a systematic approach to sonography prior to the patient encounter (Fig. 2). ${ }^{11,29,33,47,57-59}$

Patient discomfort and the intimate nature of endovaginal sonography encourage the need of simulationbased learning. Our systematic review reports significant improvement in clinical knowledge, skills and behaviors; and moderate effects for patient-related outcomes with the use of US simulation in training. ${ }^{11,15,24,67}$ However, the present studies failed to demonstrate a compelling body of evidence to support widespread adoption of US simulation-based OB GYN education to improve US performance skills.

Trainees with varied exposure to simulation found US simulation to be useful. Trainees also expressed a desire for more substantial incorporation of US simulation in their training. ${ }^{51}$ There is limited but supportive literature on the usefulness of OB GYN US simulation, which reveals that it not only improves the scanning skills of trainees and detection rates of abnormal findings but also helps providers preserve their skills. It is not surprising to see transferability of US skills to the clinical area, though not many studies investigated this effect. Despite the cost, integration of US simulators in medical education seems to have a positive implication on the scanning and interpretation skills of trainees.

We hope that this review will encourage various training programs to include US simulation in the education of their trainees with the ultimate goal of improving patient safety. More extensive clinical trials are needed to assess the long-term impact of US simulation on clinical 


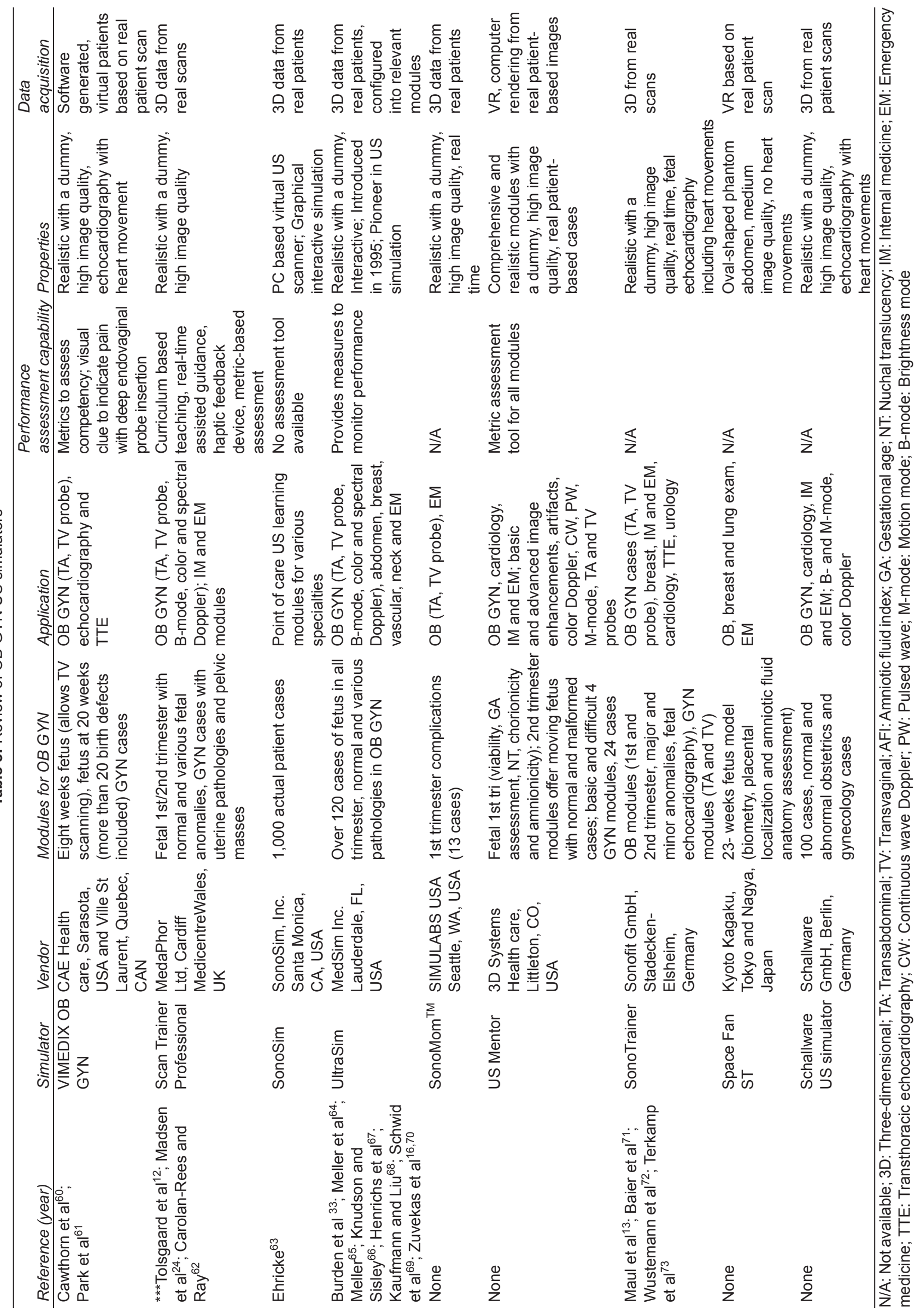




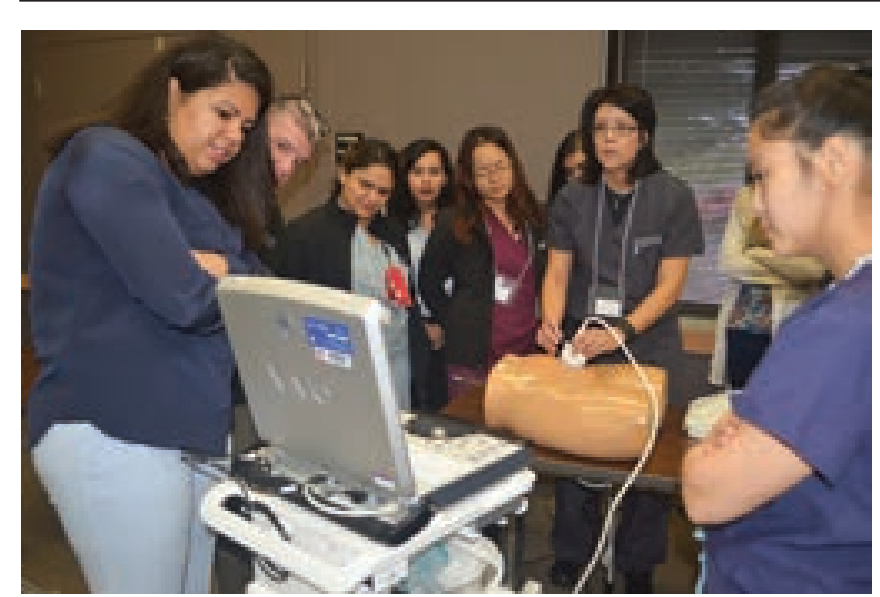

Fig. 2: Simulation of ultrasound-guided procedures

performance with the use of a comprehensive curriculum including advanced simulators. Given that there has been only one randomized trial to date which tested the impact of US education incorporating a US simulator, additional randomized controlled trials are called for. ${ }^{11}$ Further studies are needed to specify the number of sessions required to acquire and retain US skills, perform cost analysis, and assess validity and feasibility of the most recent US simulators.

\section{REFERENCES}

1. Royal College of Obstetricians and Gynaecologists. Trainees Survey; London: RCOG; 2010.

2. Tolsgaard MG, Rasmussen MB, Tappert C, Sundler M, Sorensen JL, Ottesen B, Ringsted C, Tabor A. Which factors are associated with trainees' confidence in performing obstetric and gynecological ultrasound examinations? Ultrasound Obstet Gynecol 2014 Apr;43(4):444-451.

3. Moore CL, Copel JA. Point-of-care ultrasonography. N Engl J Med [Internet]. 2011 Feb;364(8):749-757. Available from: http:/ / www.nejm.org/doi/full/10.1056/NEJMra0909487/ ninternal-pdf:/ /1587 / Moore and Copel - 2011 - Point-of-Care Ultrasonography.html.

4. Vallabh-Patel V, Mendez M, Kupesic Plavsic S. The importance of multimodality pelvic ultrasound simulation in teaching of obstetrics and gynecology residents. Donald Sch J Ultrasound Obs Gynecol 2014;8(1):1-5.

5. Jang TB, Ruggeri W, Dyne P, Kaji AH. Learning curve of emergency physicians using emergency bedside sonography for symptomatic first-trimester pregnancy. J Ultrasound Med 2010 Oct;29(10):1423-1428.

6. American Institute of Ultrasound in Medicine. AIUM practice guideline for the performance of obstetric ultrasound examinations. J Ultrasound Med 2013 Jun;32(6):1083-1101.

7. ISUOG Education Committee recommendations for basic training in obstetric and gynecological ultrasound. Ultrasound Obstet Gynecol 2014 Jan;43(1):113-116.

8. ISUOG Education Committee. Update on proposed minimum standards for ultrasound training for residents in Ob/Gyn. Ultrasound Obstet Gynecol 1996;8:363-366.

9. Hertzberg BS, Kliewer MA, Bowie JD, Carroll BA, DeLong DH, Gray L, Nelson RC. Physician training requirements in sonography: how many cases are needed for competence? AJR Am J Roentgenol 2000 May;174(5):1221-1227.

10. Gracias VH, Frankel H, Gupta R, Reilly PM, Gracias F, Klein W, Nisenbaum H, Schwab CW. The role of positive examinations in training for the focused assessment sonogram in trauma (FAST) examination. Am Surg 2002 Nov;68(11):1008-1011.

11. Chalouhi GE, Bernardi V, Ville Y. Ultrasound simulators in obstetrics and gynecology: state of the art. Ultrasound Obstet Gynecol 2015 Sep;46(3):255-263.

12. Tolsgaard MG, Ringsted C, Dreisler E, Nørgaard LN, Petersen JH, Madsen ME, Freiesleben NL, Sørensen JL, Tabor A. Sustained effect of simulation-based ultrasound training on clinical performance: a randomized trial. Ultrasound Obstet Gynecol 2015 Sep;46(3):312318.

13. Maul H, Scharf A, Baier P, Wüstemann M, Günter HH, Gebauer G, Sohn C. Ultrasound simulators: experience with the SonoTrainer and comparative review of other training systems. Ultrasound Obstet Gynecol 2004 Oct;24(5):581-585.

14. Newey VR, Nassiri DK, Bhide A, Thilaganathan B. Nuchal translucency thickness measurement: repeatability using a virtual ultrasound scanner. Ultrasound Obstet Gynecol 2003 Jun;21(6):596-601.

15. Ewigman BG, Crane JP, Frigoletto FD, LeFevre ML, Bain RP, McNellis D. Effect of prenatal ultrasound screening on perinatal outcome. RADIUS Study Group. N Engl J Med 1993 Sep;329(12):821-827.

16. Lee K, Kim SY, Choi SM, Kim JS, Lee BS, Seo K, Lee YH, Kim DK. Effectiveness of prenatal ultrasonography in detecting fetal anomalies and perinatal outcome of anomalous fetuses. Yonsei Med J 1998 Aug;39(4):372-382.

17. Chalouhi GE, Bernardi V, Ville Y. Ultrasound simulators in obstetrics and gynecology: State of the art. Ultrasound Obstet Gynecol. 2015;46(3):255-263.

18. Eurenius K, Axelsson O, Cnattingius S, Eriksson L, Norsted T. Second trimester ultrasound screening performed by midwives; sensitivity for detection of fetal anomalies. Acta Obstet Gynecol Scand [Internet]. 1999 Feb;78(2):98-104. Available from: http://www.ncbi.nlm.nih.gov/pubmed/10023870.

19. Pittini R, Oepkes D, Macrury K, Reznick R, Beyene J, Windrim $R$. Teaching invasive perinatal procedures: assessment of a high fidelity simulator-based curriculum. Ultrasound Obstet Gynecol 2002 May;19(5):478-483.

20. Heer IM, Middendorf K, Müller-Egloff S, Dugas M, Strauss A. Ultrasound training: the virtual patient. Ultrasound Obstet Gynecol 2004 Sep;24(4):440-444.

21. Staboulidou I, Freitag U, Marquardt R, Wüstemann M, Hillemanns P, Scharf A. [Quality assured ultrasound simulation training for the detection of fetal malformations - can a training benefit be evidenced?]. Z Geburtshilfe Neonatol [Internet]. 2006 Aug;210(4):135-140. (Ger). Available from: http:/ / www.ncbi.nlm.nih.gov/pubmed/16941306.

22. Burden CA, Preshaw J, Grant S. Virtual reality simulation ultrasound training in obstetrics and gynaecology. Arch Dis Child Fetal Neonata 2011 Jun;96 (Suppl 1):Fa56.

23. Burden C, Preshaw J, White P, Draycott TJ, Grant S, Fox R. Usability of virtual-reality simulation training in obstetric ultrasonography: a prospective cohort study. Ultrasound Obstet Gynecol 2013 Aug;42(2):213-217.

24. Madsen ME, Konge L, Nørgaard LN, Tabor A, Ringsted C, Klemmensen AK, Ottesen B, Tolsgaard MG. Assessment of performance measures and learning curves for use of a virtual-reality ultrasound simulator in transvaginal 
ultrasound examination. Ultrasound Obstet Gynecol 2014 Dec;44(6):693-699.

25. Moak JH, Larese SR, Riordan JP, Sudhir A, Yan G. Training in transvaginal sonography using pelvic ultrasound simulators versus live models: a randomized controlled trial. Acad Med [Internet]. 2014 Jul;89(7):1063-1068. Available from: http:// content.wkhealth.com/linkback/openurl?sid=WKPTLP:lan dingpage\&an=00001888-201407000-00032.

26. Levi S, Schaaps JP, De Havay P, Coulon R, Defoort P. End-result of routine ultrasound screening for congenital anomalies: the Belgian Multicentric Study 1984-92. Ultrasound Obstet Gynecol [Internet]. 1995 Jun;5(6):366-371. Available from: http:/ /www.ncbi.nlm.nih.gov/pubmed/7552796.

27. Bofill JA, Sharp GH. Obstetric sonography. Who to scan, when to scan, and by whom. Obstet Gynecol Clin North Am 1998 Sep;25(3):465-478.

28. Crane JP, LeFevre ML, Winborn RC, Evans JK, Ewigman BG, Bain RP, Frigoletto FD, McNellis D. A randomized trial of prenatal ultrasonographic screening: impact on the detection, management, and outcome of anomalous fetuses. The RADIUS Study Group. Am J Obstet Gynecol 1994 Aug;171(2): 392-399.

29. Burden C, Preshaw J, White P, Draycott TJ, Grant S, Fox R. Validation of virtual reality simulation for obstetric ultrasonography: a prospective cross-sectional study. Simul Healthc [Internet]. 2012 Oct;7(5):269-273. Available from: http:/ / www. ncbi.nlm.nih.gov/pubmed/22878584.

30. Akoma UN, Shumard KM, Street L, Brost BC, Nitsche JF. Impact of an inexpensive anatomy-based fetal pig simulator on obstetric ultrasound training. J Ultrasound Med 2015 Oct;34(10):1793-1799.

31. Biggio JR Jr. Prenatal screening for fetal aneuploidy: time to examine where we are and where we are going. Am J Obstet Gynecol 2016 Jun;214(6):673-675.

32. Khurshid N, Heiser T, Trampe B, Grady M, Stewart K, Shah D, Iruretagoyena J. Current trends in ultrasound guided invasive procedures and impact on MFM fellowship training. Am J Obstet Gynecol 2014 Jan;210(1 Suppl):S80-S81.

33. Burden C, Preshaw J, White P, Draycott TJ, Grant S, Fox R. Usability of virtual-reality simulation training in obstetric ultrasonography: A prospective cohort study. Ultrasound Obstet Gynecol. 2013;42(2):213-217.

34. Nitsche JF, Brost BC. The use of simulation in maternal-fetal medicine procedure training. Semin Perinatol [Internet]. 2013 Jun;37(3):189-198. Available from: http://dx.doi.org/ 10.1053/j.semperi.2013.02.011.

35. McWeeney DT, Schwendemann WD, Nitsche JF, Rose $\mathrm{CH}$, Davies NP, Watson WJ, Brost BC. Transabdominal and transcervical chorionic villus sampling models to teach maternal-fetal medicine fellows. Am J Perinatol 2012 Aug;29(7): 497-502.

36. Nitsche JF, McWeeney DT, Schwendemann WD, Rose CH, Davies NP, Watson W, Brost BC. In-utero stenting: development of a low-cost high-fidelity task trainer. Ultrasound Obstet Gynecol 2009 Dec;34(6):720-723.

37. Zubair I, Marcotte MP, Weinstein L, Brost BC. A novel amniocentesis model for learning stereotactic skills. Am J Obstet Gynecol 2006 Mar;194(3):846-848.

38. Khurshid N, Trampe B, Heiser T, Birkeland L, Duris E, Stewart K, Shah D, Iruretagoyena J. 420: impact of an amniocentesis simulation curriculum for training in MFM fellowship program. Am J Obstet Gynecol [Internet]. 2014
Jan;210(1):S212-S213. Available from: http:/ /linkinghub. elsevier.com/retrieve/pii/S0002937813015184.

39. Peeters SH, Akkermans J, Slaghekke F, Bustraan J, Lopriore E, Haak MC, Middeldorp JM, Klumper FJ, Lewi L, Devlieger R, et al. Simulator training in fetoscopic laser surgery for twin-twin transfusion syndrome: a pilot randomized controlled trial. Ultrasound Obstet Gynecol [Internet]. 2015 Sep;46(3):319-326. Available from: http:/ /ovidsp.ovid.com/ ovidweb.cgi? $\mathrm{T}=\mathrm{JS} \& \mathrm{PAGE}=$ reference $\& \mathrm{D}=$ prem $\& N E W S=\mathrm{N}$ $\& \mathrm{AN}=26036333$.

40. Shumard KM, Akoma UN, Street LM, Brost BC, Nitsche JF. Development of a novel task trainer for second trimester ultrasound-guided uterine evacuation. Simul Healthc 2015 Feb;10(1):49-53.

41. Girzadas DV Jr, Antonis MS, Zerth H, Lambert M, Clay L, Bose S, Harwood R. Hybrid simulation combining a high fidelity scenario with a pelvic ultrasound task trainer enhances the training and evaluation of endovaginal ultrasound skills. Acad Emerg Med 2009 May;16(5):429-435.

42. Monsky WL, Levine D, Mehta TS, et al. Using a sonographic simulator to assess residents before overnight call. Am J Roentgenol. 2002;178(1):35-39.

43. Khurshid N, Trampe B, Iruretagoyena J, Shah D, Stewart K. 419: so you think you can scan? A competency based ultrasound curriculum for MFM fellows. Am J Obstet Gynecol 2014 Jan;210(1):S212.

44. Issenberg SB, McGaghie WC, Petrusa ER, Lee Gordon D, Scalese RJ. Features and uses of high-fidelity medical simulations that lead to effective learning: a BEME systematic review. Med Teach 2005 Jan;27(1):10-28.

45. van der Gijp A, van der Schaaf MF, van der Schaaf IC, Huige JC, Ravesloot CJ, van Schaik JP, Ten Cate TJ. Interpretation of radiological images: towards a framework of knowledge and skills. Adv Health Sci Educ Theory Pract 2014 Oct;19(4):565-580.

46. Krupinski EA. Current perspectives in medical image perception. Atten Percept Psychophys [Internet]. 2010 Jul;72(5):12051217. Available from: http:/ / www.pubmedcentral.nih.gov/ articlerender.fcgi? artid $=3881280 \&$ tool $=$ pmcentrez\&renderty pe $=$ abstract.

47. Tolsgaard MG, Todsen T, Sorensen JL, Ringsted C, Lorentzen T, Ottesen B, Tabor A. International multispecialty consensus on how to evaluate ultrasound competence: a Delphi consensus survey. PLoS One 2013;8(2):e57687.

48. Alsalamah A., Campo R., Hood K., Amso N. Face and content validity of the scantrainer ultrasound simulator [Internet]. Gynecol Surg 2014;11(1)(Suppl 1):107-108. Available from: http:/ /ovidsp.ovid.com/ovidweb.cgi?T=JS\&PAGE=referen ce\&D=emed12\&NEWS=N\&AN=71644179

49. Al-Memar M, Saso S, Bobdiwala S, Ameye L, Stalder C, Joash K, Timmerman D, Bourne T. Validation of a virtual reality simulator for the use of transvaginal ultrasound in gynaecology and early pregnancy. BJOG An Int J Obstet Gynaecol 2016 Jun;123 (Suppl):212.

50. Preshaw J, Ficquet J, Burden C, Overton C, Grant S. Would it be best practice for trainees to learn ultrasound scanning in a simulated setting prior to a clinical setting. Int J Gynecol Obstet 2012 Oct;119(53):S457.

51. Patel H, Chandrasekaran D, Myriokefalitaki E, Gebeh A, Jones K, Jeve YB; Midlands Research Collaborative in Obstetrics \& Gynecology. The role of ultrasound simulation in 
Obstetrics and Gynecology Training: a UK trainees' perspective. Simul Healthc 2016 Oct;11(5):340-344.

52. Palter VN, Grantcharov T, Harvey A, Macrae HM. Ex vivo technical skills training transfers to the operating room and enhances cognitive learning: a randomized controlled trial. Ann Surg 2011 May;253(5):886-889.

53. Seymour NE, Gallagher AG, Roman SA, O'Brien MK, Bansal VK, Andersen DK, Satava RM. Virtual reality training improves operating room performance: results of a randomized, doubleblinded study. Ann Surg [Internet]. 2002 Oct;236(4):458-463. Available from: http:/ /www.ncbi.nlm.nih.gov/pmc/articles/ PMC1422600/pdf/20021000s00008p458.pdf.

54. Hiemstra E, Kolkman W, van de Put MA, Jansen FW. Retention of basic laparoscopic skills after a structured training program. Gynecol Surg 2009 Sep;6(3):229-235.

55. Sarmiento J, Stewart K, Aguila J, Bagherpour A, Plavsic SK. Pelvic ultrasound simulation training models and case scenarios. Vol. 8, Donald School J Ultrasound Obstet Gynecol 2014 Jan-Mar;8(1):22-30.

56. Cook DA, Hatala R, Brydges R, Zendejas B, Szostek JH, Wang AT, Erwin PJ, Hamstra SJ. Technology-enhanced simulation for health professions education: a systematic review and meta-analysis. JAMA [Internet]. 2011 Sep;306(9): 978-988. Available from: http:/ /jama.ama-assn.org/content/ 306/9/978.abstract \nhttp:/ /jama.ama-assn.org/content/ 306/9/978.full.pdf.

57. Salvesen KA, Lees C, Tutschek B. Basic European ultrasound training in obstetrics and gynecology: where are we and where do we go from here? Ultrasound Obstet Gynecol [Internet]. 2010 Nov [cited 2016 Sep 25];36(5):525-529. Available from: http:/ / www.ncbi.nlm.nih.gov/pubmed/20981718.

58. Nitsche JF, Brost BC. Obstetric ultrasound simulation. Semin Perinatol 2013 Jun;37(3):199-204.

59. McGaghie WC, Issenberg SB, Petrusa ER, Scalese RJ. A critical review of simulation-based medical education research: 2003-2009. Med Educ 2010 Jan;44(1):50-63.

60. Cawthorn TR, Nickel C, O'Reilly M, Kafka H, Tam JW, Jackson LC, Sanfilippo AJ, Johri AM. Development and evaluation of methodologies for teaching focused cardiac ultrasound skills to medical students. J Am Soc Echocardiogr 2014 Mar;27(3):302-309.

61. Parks AR, Atkinson P, Verheul G, Leblanc-Duchin D. Can medical learners achieve point-of-care ultrasound competency using a high-fidelity ultrasound simulator?: a pilot study. Crit Ultrasound J 2013 Nov;5(1):9.

62. Carolan-Rees G, Ray AF. The ScanTrainer obstetrics and gynaecology ultrasound virtual reality training simulator: a cost model to determine the cost viability of replacing clinical training with simulation training. Ultrasound 2015 May;23(2):110-115.

63. Ehricke HH. SONOSim3D: a multimedia system for sonography simulation and education with an extensible case database. Eur J Ultrasound 1998 Aug;7(3):225-300.

64. Meller G, Tepper R, Bergman M, Anderhub B. The tradeoffs of successful simulation. Stud Health Technol Inform 1997;39:565-571.

65. Meller G. A typology of simulators for medical education. J Digit Imaging 1997 Aug;10(3 Suppl 1):194-196.

66. Knudson MM, Sisley AC. Training residents using simulation technology: experience with ultrasound for trauma. J Trauma 2000 Apr;48(4):659-665.

67. Henrichs B, Rule A, Grady M, Ellis W. Nurse anesthesia students' perceptions of the anesthesia patient simulator: a qualitative study. AANA J 2002 Jun;70(3):219-225.

68. Kaufmann C, Liu A. Trauma training: virtual reality applications. Stud Health Technol Inform [Internet]. 2001;81:236-241. Available from: http://www.ncbi.nlm.nih.gov/pubmed/ 11317747

69. Schwid HA, Rooke GA, Carline J, Steadman RH, Murray WB, Olympio M, Tarver S, Steckner K, Wetstone S; Anesthesia Simulator Research Consortium. Evaluation of anesthesia residents using mannequin-based simulation: a multiinstitutional study. Anesthesiology [Internet]. 2002 Dec;97(6):14341444. Available from: http:/ /ovidsp.ovid.com/ovidweb. cgi? $\mathrm{T}=\mathrm{JS} \& \mathrm{CSC}=\mathrm{Y} \& \mathrm{NEWS}=\mathrm{N} \& \mathrm{PAGE}=$ fulltext $\& \mathrm{D}=\mathrm{yrovftf}$ \&AN=00000542-200212000-00015\nhttp:/ /www.ovid.com/ site/resources/expert_search/healthexp.html.

70. Zuvekas SH, Banthin JS, Selden TM. How would mental health parity affect the marginal price of care? Health Serv Res [Internet]. 2001 Feb;35(6):1207-1227. Available from: http:/ / www.pubmedcentral.nih.gov/articlerender.fcgi?artid=1089 $187 \&$ tool $=$ pmcentrez\&rendertype $=$ abstract

71. Baier P, Scharf A, Sohn C. Der Echtzeit Ultraschallsimulator. Eine neue Methode zum Training in der Ultraschalldiagnostik [New ultrasound simulation system: a method for training and improved quality management in ultrasound examination]. Z Geburtshilfe Neonatol. 2001 Nov-Dec;205(6):213-217.

72. Wustemann M, Scharf A, Maul H, Baier P, Sohn C. New ultrasound simulation system: an effective training method to improve the examiner's experience for the first trimester screening for chromosomal abnormalities using sonography. Geburtshilfe Frauenheilkd 2002 Jan;62(12):1183-1187.

73. Terkamp C, Kirchner G, Wedemeyer J, Dettmer A, Kielstein J, Reindell H, Bleck J, Manns M, Gebel M. Simulation of abdomen sonography. Evaluation of a new ultrasound simulator. Ultraschall Med 2003 Aug;24(4):239-244. 